Research Article

\title{
Experimental Study on Bearing Characteristics and Soil Deformation of Necking Pile with Cap Using Transparent Soils Technology
}

\author{
Zhijun Xu $\mathbb{D}$ and Zhaoxiang Guo \\ College of Civil Engineering, Henan University of Technology, Zhengzhou 450001, China \\ Correspondence should be addressed to Zhijun Xu; zj.xu_hust@qq.com
}

Received 17 December 2020; Revised 23 February 2021; Accepted 9 March 2021; Published 24 March 2021

Academic Editor: Bingxiang Yuan

Copyright (C) 2021 Zhijun Xu and Zhaoxiang Guo. This is an open access article distributed under the Creative Commons Attribution License, which permits unrestricted use, distribution, and reproduction in any medium, provided the original work is properly cited.

\begin{abstract}
This paper will employ the transparent soil experiment technology to explore the influences of shallow necking on the vertical bearing capacity of single pile with cap. Model experiment is carried out on one intact pile and nine shallow necking piles. The load-settlement curves of all piles are obtained, which are used to study bearing characteristics of piles. The displacement fields of soil around piles are employed to investigate the reasons for the loss of vertical bearing capacity of piles with shallow necking. The vertical bearing capacity is greatly reduced which is caused by shallow necking. When the axial dimension of necking is the same, the larger the radial size is, the greater the loss of vertical bearing capacity is. When the radial dimension of necking is the same, the greater the axial size is, the greater the loss of vertical bearing capacity is. The soil near the pile shaft and under the pile cap produces a large area of vertical downward deformation, which causes the relative displacement between the pile shaft and the soil to greatly reduce. Therefore, it is easy that the necking piles with caps develop negative friction, which causes the vertical bearing capacity of piles to reduce. When the radial dimension of the shallow necking is $80 \%$ of pile diameter, the pile is easy to be damaged.
\end{abstract}

\section{Introduction}

With the rapid development of underground space, pile foundation is widely used in civil engineering because of its high bearing capacity, small settlement, and so on. However, due to construction technology, site geological conditions, construction persons, operation procedures, and other reasons, piles are prone to develop various defects. The probability of defective pile is about $9.1 \%$ for bored piles [1]. Necking pile is one of the main defects which can cause the vertical bearing capacity of piles to lose because load transmission cannot be performed effectively [2]. Therefore, it is of great engineering and economic significance to study the bearing characteristics of necking piles.

The research of necking pile is focused on the causes of defects, detection, and so on. Schilder et al. [3] developed a device for detecting pile integrity by arranging the Fabry-Perot interferometer sensor and the fiber Bragg grating sensor outside the pile body. Ni et al. [4] used field tests to study the wavelet transform technology in the identification of defective piles. Singh et al. [5] discussed the advantages and disadvantages of the low-strain method and cross-hole acoustic logging method through the field bridge foundation integrity identification test. Wang and An [6] used the threedimensional nonlinear finite-infinite element method to compare and analyze the necking pile and the normal pile. It is found that the shallower the depth of the necking, the greater the settlement of the pile cap when the defect degree is the same. To sum up, there is no literature to explain the internal deformation of soil around necking pile with cap, and the systematic research on the interaction of pile-soilcap with different necking has not been reported.

In recent years, transparent soil experiment technology has been widely used to study the deformation of soil around piles. Iskander et al. [7] first found that the transparent saturated two-phase medium has the mechanical properties 
of soil. Yuan et al. [8] compared the stress-strain curves of transparent sand made of fused silica sand and natural sand and found that the two are particularly similar, and the failure mode of transparent sand is basically the same as that of standard sand. Ni et al. [9] used the transparent soil model test to study the influence of pile penetration on soil movement in clay. Hurd et al. [10] studied the influence of auger drilling on surrounding soil during drilling using artificial transparent clay. Kong et al. [11] used the transparent soil test to study the deformation law of soil around the pile under inclined uplift force. Sang et al. [12] revealed the deformation law of the soil around the pile cap through the transparent soil test technology and studied the soil deformation around the pile tip and the foundation pile. Yuan et al. [13] proposed an improved three-dimensional (3D) displacement measuring system, which uses particle image velocimetry (PIV) to measure the full three-dimensional displacement fields around laterally loaded piles in transparent soil. Sang et al. [14] introduced a displacement measuring device for hydraulic gradient tests of transparent soil, simulated the stress characteristics of soil around horizontal load pile under high stress field, and obtained the three-dimensional displacement of transparent soil under a laterally loaded pile. To sum up, the transparent soil experiment technology can be used to well observe the deformation of soil around the pile, which solves the interference of traditional contact soil experiment.

Based on transparent soil technology, model experiments are carried out on one intact pile with cap and nine shallow necking piles with caps. The load-settlement curves and the displacement field diagram of soil around the pile are obtained. The vertical bearing capacity of intact pile and necking piles and the load transfer mechanism are investigated through soil deformation around the piles. Finally, through soil deformation around the piles, the reasons for the reduction of vertical bearing capacity of shallow necking piles with caps are investigated.

\section{Loading Design of Transparent Soil Model Experiment}

2.1. Transparent Soil Parameters. The transparent soil is made using fused silica sand, $\mathrm{n}$-dodecane, and 90\# white oil. The particle size of fused silica sand is $0.5 \mathrm{~mm}-2 \mathrm{~mm}$, and the purity is $99.9 \%$. The particle size distribution of fused silica sand is shown in Figure 1. The physical parameters of fused silica sand are shown in Table 1. n-Dodecane and 90\# white oil are mixed according to the volume ratio of $1: 4.75$ to make the pore solution of transparent soil. At room temperature $20^{\circ} \mathrm{C}$, the refractive index of the pore solution is 1.4590 , which matches the refractive index of fused silica sand. The configured transparent soil belongs to saturated sand, and the sample is shown in Figure 2. Speckle image under laser irradiation is shown in Figure 3.

2.2. Experiment Device and Scheme. The loading device of transparent soil model experiment is shown in Figure 4, which is composed of a CCD industrial camera, a small

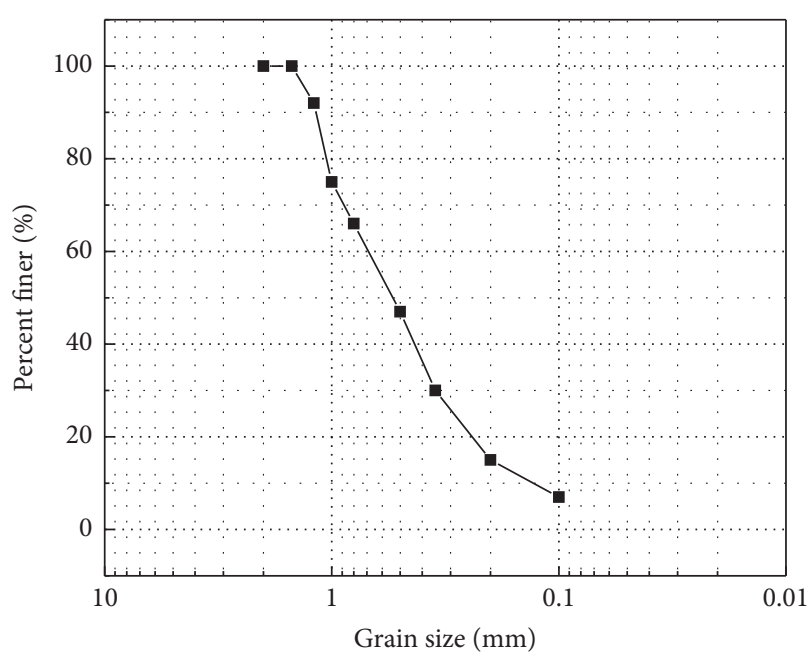

Figure 1: Particle size curve of fused silica sand.

TABLe 1: Fused quartz sand parameters.

\begin{tabular}{lccccc}
\hline$C_{\mathrm{u}}$ & $C_{\mathrm{c}}$ & $\rho_{\mathrm{d}}\left(\mathrm{g} \cdot \mathrm{cm}^{3}\right)$ & $\rho_{\mathrm{dmax}}\left(\mathrm{g} \cdot \mathrm{cm}^{3}\right)$ & $\rho_{\mathrm{d} \min }\left(\mathrm{g} \cdot \mathrm{cm}^{3}\right)$ & $\gamma\left(\mathrm{kN} \cdot \mathrm{m}^{3}\right)$ \\
\hline 5.45 & 2.04 & 1.4 & 1.56 & 1.18 & 2.33 \\
\hline
\end{tabular}

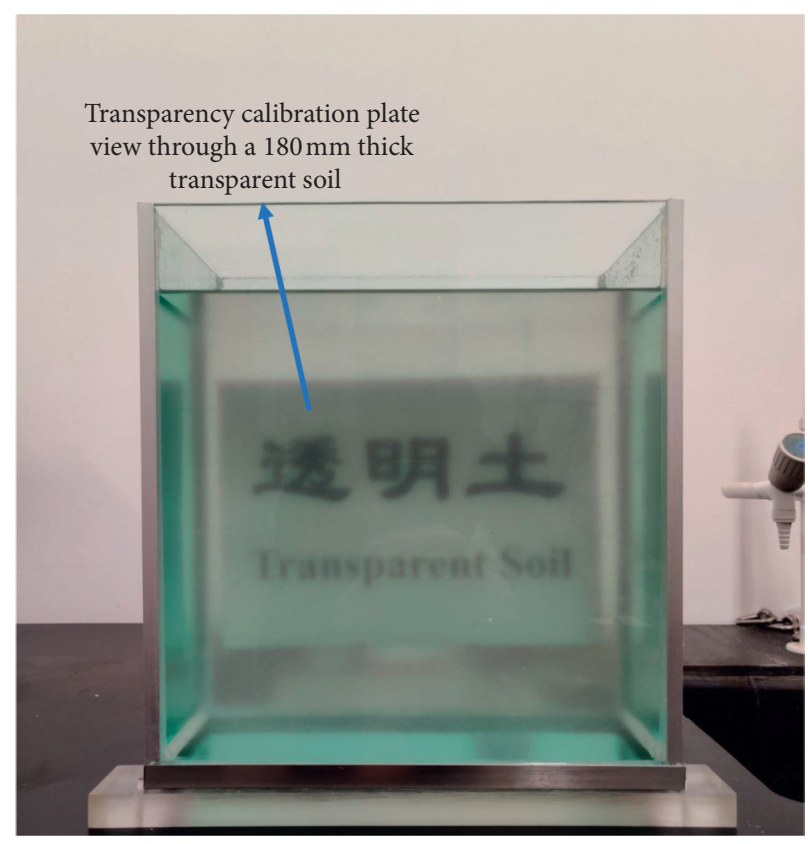

Figure 2: Transparent soil model.

loading system, a laser device, an optical prism, and an image capture and processing system [15]. The accuracy of pressure sensors is $0.3 \mathrm{~N}$, and the range and accuracy of displacement sensor are $0-600 \mathrm{~mm}$ and $0.001 \mathrm{~mm}$, respectively. The resolution of the CCD industrial camera and the focal length of the lens are $1028 \times 1536$ pixels and $16 \mathrm{~mm}$, respectively. During loading, the CCD industrial camera is set to the fixed focus mode and fixed at the same position. The layouts of the model tank, pile, and transparent soil are shown in Figure 5.

Before loading, the prepared transparent soil is put into a model tank made by glass ( $5 \mathrm{~mm}$ thickness), and then the 


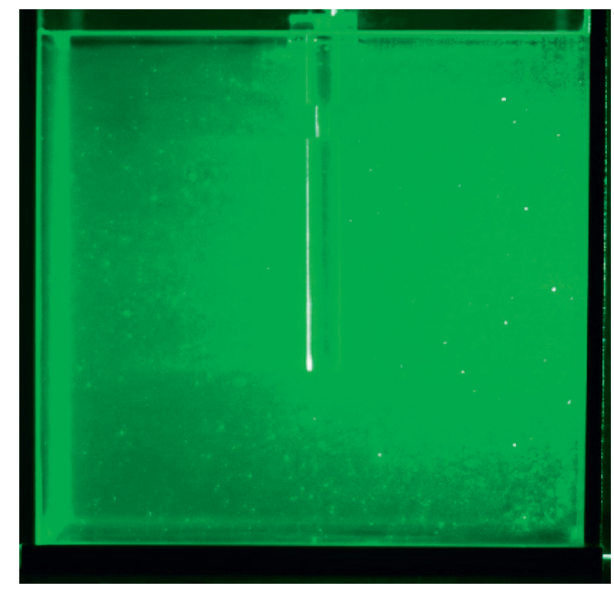

Figure 3: Speckle image under laser irradiation.

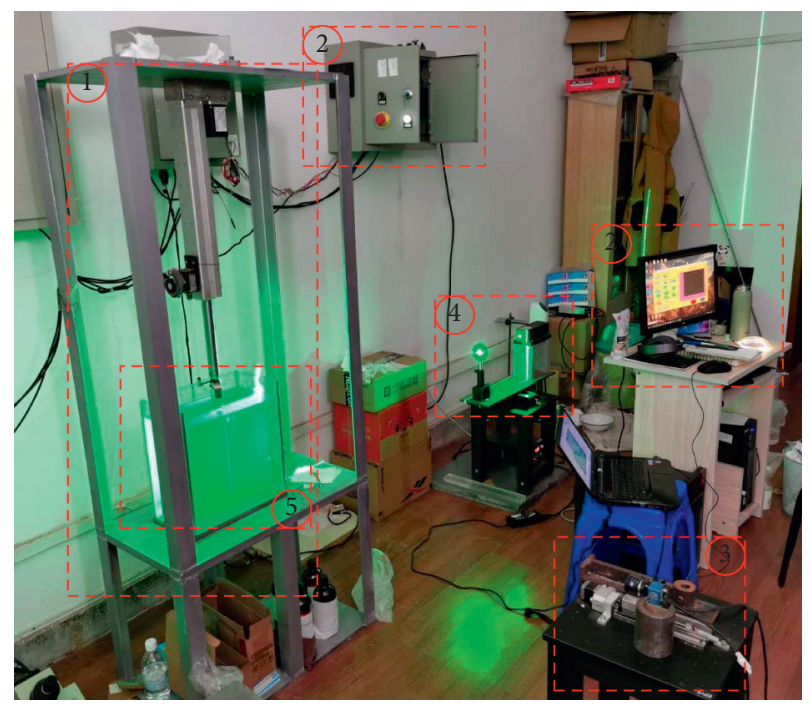

Figure 4: Components of the transparent soil model experiment set up ((1) loading device, (2) electric control box, (3) image acquisition system, (4) surface laser d-device, and (5) transparent soil model tank)).

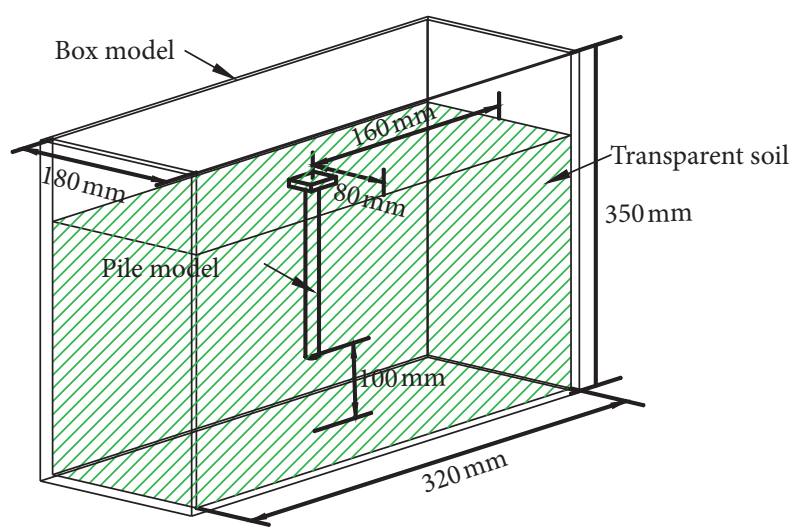

Figure 5: Box model and layout of piles and soil.

model pile is pushed into the soil. The inner dimensions such as length, width, and height of the model tank are $320 \mathrm{~mm}$, $180 \mathrm{~mm}$, and $350 \mathrm{~mm}$, respectively. By vacuuming the transparent soil inside the model tank, the gas in the pores of the particles is removed and the pore pressure inside the soil disappears. After the vacuum is completed, model tank is placed on the loading platform and allowed to stand for 24 hours. Then, the piles with caps are loaded in stages through the control system. Before loading, the surface laser is aligned with the axis of model pile to ensure that the image plane is on the surface laser. The CCD industrial camera is placed about $1000 \mathrm{~mm}$ away from model tank, and its optical axis is perpendicular to the surface laser. During loading, an image is captured every time the settlement of pile cap is $1 \mathrm{~mm}$. Then, MatPIV software is employed to process the captured images.

Based on Technical Code for Building Pile Foundations (JGJ106-2014) [16], the load is carried out on the caps according to the stepped loading method. The load at each step is the maximum load or $1 / 10$ of the estimated bearing capacity. After each load is conducted, the settlement of pile cap is recorded until the settlement has completed. The basis for judging the completion of the settlement of each step is that the settlement of the cap is less than $0.1 \mathrm{~mm} /$ hour, and it occurs twice in a row. When a sudden settlement occurs at a certain loading step or the settlement is greater than the allowable value, the loading ends. In order to ensure the consistency of the experiment conditions, when preparing model experiment, the gravity and height of the transparent soil in model tank are controlled to be consistent to ensure the same density of the transparent soil during loading. Model experiment is repeated three times, and the average results of three experiments are taken. Speckle image is a set of images that is similar to the average value. The whole experiment is in a dark room.

2.3. Model Pile Design and Its Materials. Model experiment is carried out on one intact pile with cap and nine shallow necking piles with caps. According to the similarity theory [17], the size of model piles is designed, and the reduced scale is $1: 50$. The pile diameter $(D)$ and length $(L)$ are $20 \mathrm{~mm}$ and $200 \mathrm{~mm}$, respectively. The sizes of pile cap are $40 \mathrm{~mm}$ for length, $40 \mathrm{~mm}$ for width, and $15 \mathrm{~mm}$ for height. Necking position and parameters are shown in Table 2 [18]. To conveniently investigate, the dimension symbols of necking are defined in Figure 6. Model pile is made by transparent plexiglass (polymethyl methacrylate, PMMA). In order to be consistent with the friction coefficient of engineering piles, model piles are polished with gauze. Young's modulus of model pile is $532.7 \mathrm{MPa}$ at $20^{\circ} \mathrm{C}$, and the physical diagram of model pile is shown in Figure 7.

Note that $L, M$, and $S$ represent that the axial dimension of necking is $20 \mathrm{~mm}, 10 \mathrm{~mm}$, and $5 \mathrm{~mm}$, respectively; $W, M$, and $T$ represent that the radial dimension of necking is $2 \mathrm{~mm}, 6 \mathrm{~mm}$, and $8 \mathrm{~mm}$, respectively. The distance between the bottom of necking and pile tip is $140 \mathrm{~mm}$.

\section{Experiment Results Investigations}

According to the load displacement curves, the influences of shallow necking on the vertical bearing capacity of piles with 
TABLE 2: Model piles and parameters of shallow necking.

\begin{tabular}{lcc}
\hline Model piles & $L_{\mathrm{d}}(\mathrm{mm})$ & $L_{\mathrm{s}}(\mathrm{mm})$ \\
\hline Intact pile & - & - \\
SLW pile & 20 & 2 \\
SLM pile & 20 & 6 \\
SLT pile & 20 & 8 \\
SMW pile & 10 & 2 \\
SMM pile & 10 & 6 \\
SMT pile & 10 & 8 \\
SSW pile & 5 & 2 \\
SSM pile & 5 & 6 \\
SST pile & 5 & 8 \\
\hline
\end{tabular}

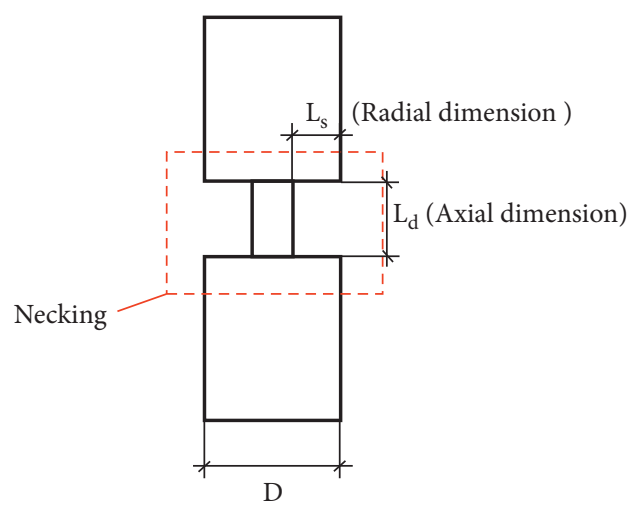

FIgURE 6: Symbols of neck dimensions.

caps will be investigated. Through the particle movement and load transfer of soil around piles, the reason why the shallow necking affects the vertical bearing capacity of piles with caps will be also investigated.

3.1. Vertical Bearing Capacity Investigation. Figure 8 gives the load-settlement curves of piles. According to Technical Code for Building Pile Foundations (JGJ106-2014), the load when the settlement reaches $4 \mathrm{~mm}$ is the vertical ultimate bearing capacity of piles. The vertical ultimate bearing capacity of testing piles is $220 \mathrm{~N}$ (for SSW pile), $218 \mathrm{~N}$ (for intact pile), $215 \mathrm{~N}$ (for SSM pile), $198 \mathrm{~N}$ (for SST pile), $193 \mathrm{~N}$ (for SMW pile), $192 \mathrm{~N}$ (for SLW pile), $182 \mathrm{~N}$ (for SMM pile), $153 \mathrm{~N}$ (for SMT pile), $150 \mathrm{~N}$ (for SLM pile), and $109 \mathrm{~N}$ (for SLT pile), respectively. It can be seen that the vertical bearing capacity of SLT pile has lost by $50 \%$ through the load-settlement curves. When $L_{\mathrm{d}}=5 \mathrm{~mm}$, the necking has little effect on vertical bearing capacity, and the maximum loss of vertical bearing capacity is $9 \%$ (for SST pile). When $L_{\mathrm{d}}=5 \mathrm{~mm}$, the load-settlement curves of SSW pile, SSM pile, and SST pile are roughly distributed between that of intact pile and SLW pile. When $L_{\mathrm{d}}=10 \mathrm{~mm}$, the loadsettlement curves of SMW pile, SMM pile, and SMT pile are distributed between that of SLW pile and SLM pile. Therefore, $L_{\mathrm{d}}$ has great contribution to the vertical bearing capacity of single piles with caps.

Relationship between vertical ultimate bearing capacity and axial dimension is shown in Figure 9. Results show that vertical bearing capacity tends to be stable with the increase in axial dimension of necking when $L_{\mathrm{s}}=2 \mathrm{~mm}$, which indicates that $L_{\mathrm{s}}=2 \mathrm{~mm}$ is insensitive to vertical bearing capacity. The vertical bearing capacity decreases linearly with the increase in $L_{\mathrm{d}}$ when $L_{\mathrm{s}}=6 \mathrm{~mm}$ or $L_{\mathrm{s}}=8 \mathrm{~mm}$. Relationship between vertical ultimate bearing capacity and radial dimension is shown in Figure 10. Results show that when the axial dimension is the same, the vertical bearing capacity decreases with the increase in the radial dimension. The effect of $L_{\mathrm{s}}=8 \mathrm{~mm}$ on the vertical bearing capacity is great.

\subsection{Displacement Field Investigation of Soil around Pile.} MatPIV is an effective tool for particle image velocimetry [19]. A speckle image with the size of $100 \mathrm{~mm} \times 100 \mathrm{~mm}$ is translated downward by $1.88 \mathrm{~mm}$ to test the accuracy of image processing. Results show that from Figure 11, it is obvious that the overall displacement direction is vertical downward, which clearly describes the overall vertical downward movement of speckle image. It can measure the displacement of particles very well.

In order to facilitate investigation, the soil deformation around piles when the pile cap settlement is $4 \mathrm{~mm}$ is taken. The model experiment is symmetrically distributed along the central axis of the pile, and $1 / 2$ part of the model experiment (in the right part of model pile) is selected for investigation. The vector diagrams and contour maps of soil displacement field around piles are shown in Figures 12-16.

Soil deformations mainly distribute around pile cap and pile tip for intact pile as shown in Figure 12. However, small soil deformation develops around the pile shaft. The ranges of soil deformation are 4.5 times pile diameter under pile cap, 5 times pile diameter on the right of pile cap (area 1), 1 time pile diameter around pile shaft (area 2), and 3 times pile diameter under pile tip (area 3), respectively. In area 1, the soil under pile cap could develop large vertical stress caused by pile cap, which makes the soil near pile shaft develop inclined downward displacement. Accordingly, the relative displacement between pile shaft and soils reduces, resulting in reducing the friction resistance of the upper part of pile shaft and easily producing negative friction resistance. At the same time, the extrusion stress caused by the soil in area 1 leads to the increase in horizontal stress. The direction of principal stress in area 1 gradually changes from vertical to upward incline. The soil near surface has inclined upward displacement, and the maximum displacement occurs at the position of twice pile diameter. The soil in area 2 moves downward due to shear sliding with pile settlement. Area 3 is divided into area 3(a) and area 3(b). Area 3(a) is a compression region, and the displacement direction of soil is radial and vertical. Area $3(\mathrm{~b})$ is a transitional region, the direction of soil principal stress gradually changes from vertical down to horizontal, and the direction of soil deformation gradually changes from inclined down to horizontal right.

From Figures 13-15, the influences of $L_{\mathrm{s}}$ on the deformations of soil around piles are studied when $L_{\mathrm{d}}=20 \mathrm{~mm}$. For SLW piles, the range of soil deformation in area 1 is larger than that of intact pile. The deformation range of soil under area 1 increases by $22 \%$ comparing 


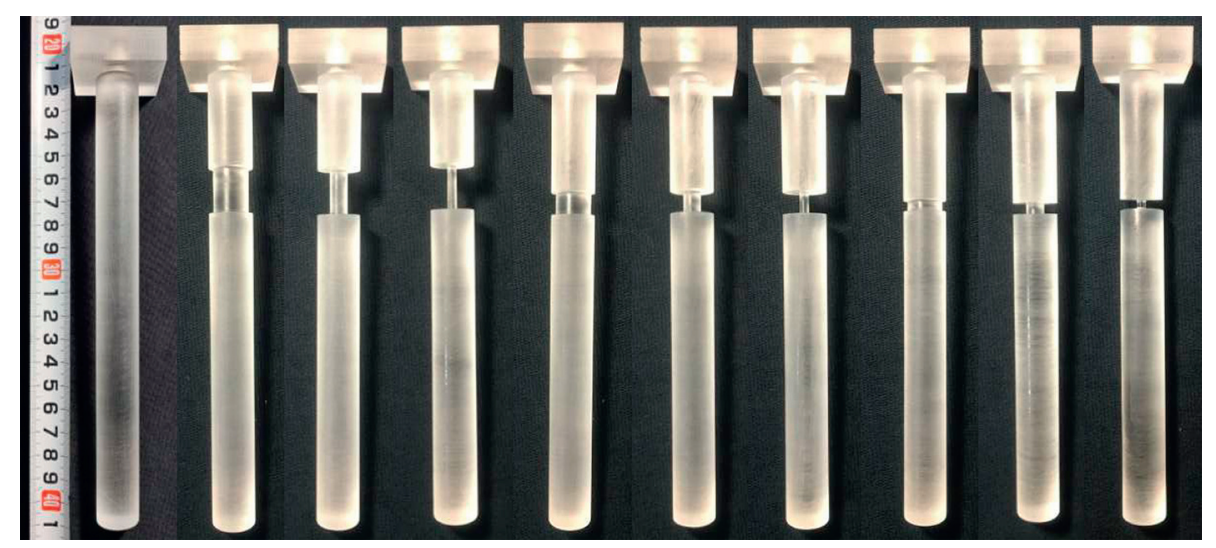

FIGURE 7: Intact pile and shallow necking piles.

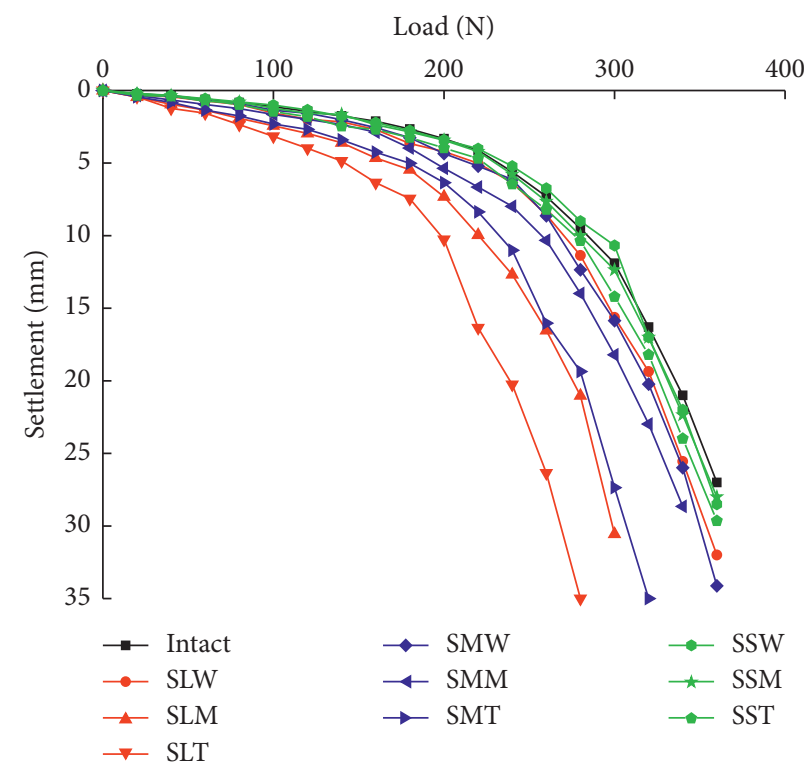

Figure 8: Load-settlement curves of piles.

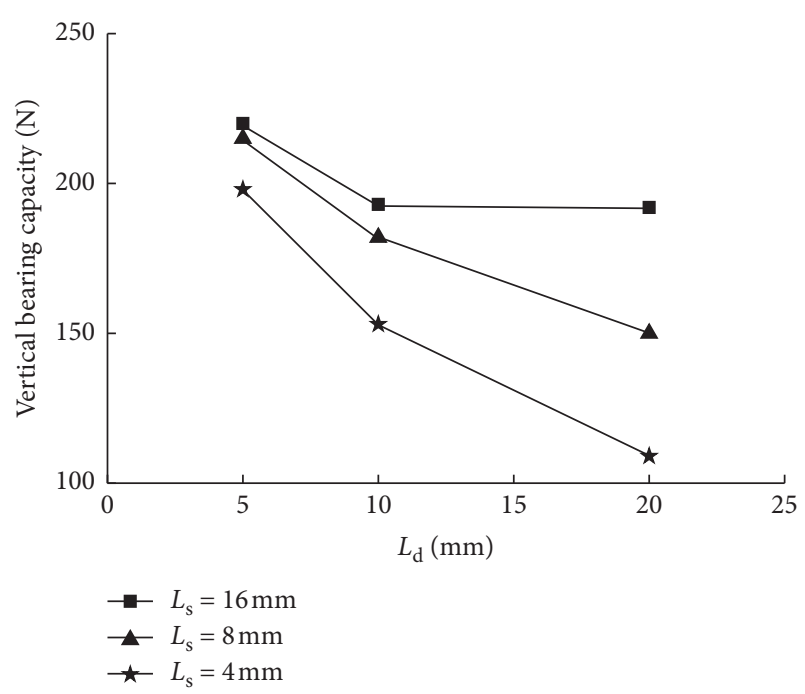

FIGURE 9: Relationship between vertical bearing capacity of piles and the size of shallow necking.

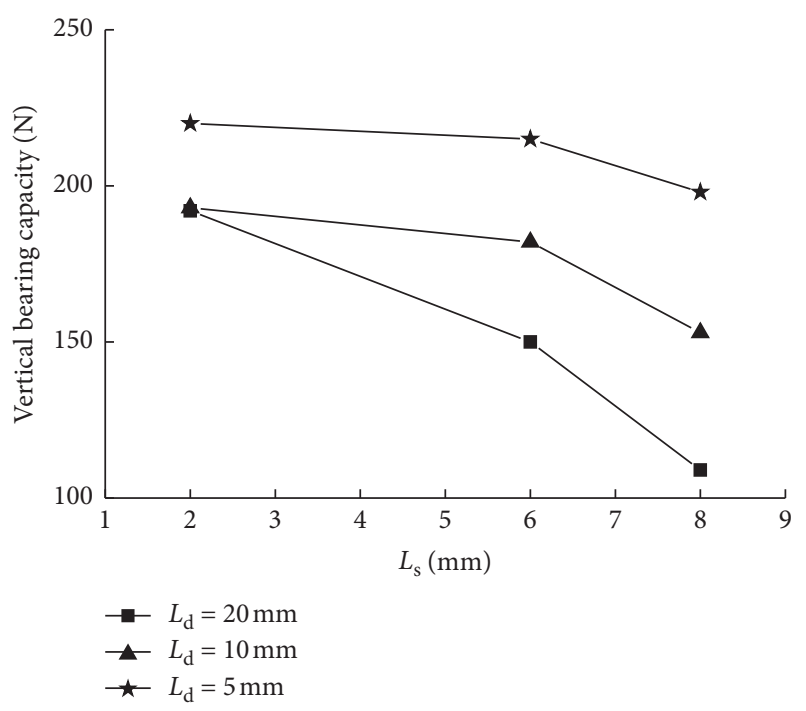

FIgURE 10: Relationship between vertical bearing capacity of piles and the size of shallow necking. 


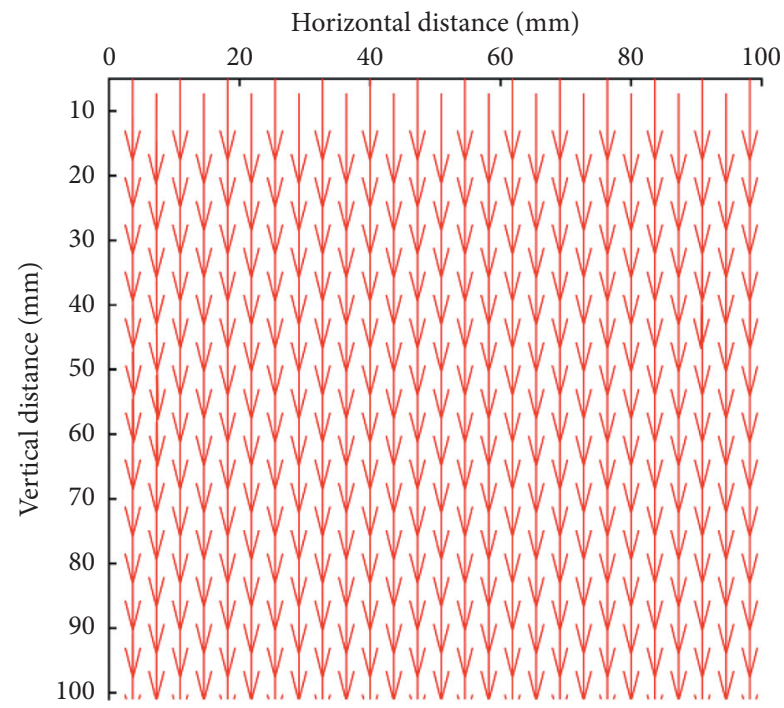

FIgURE 11: Displacement vector diagram.

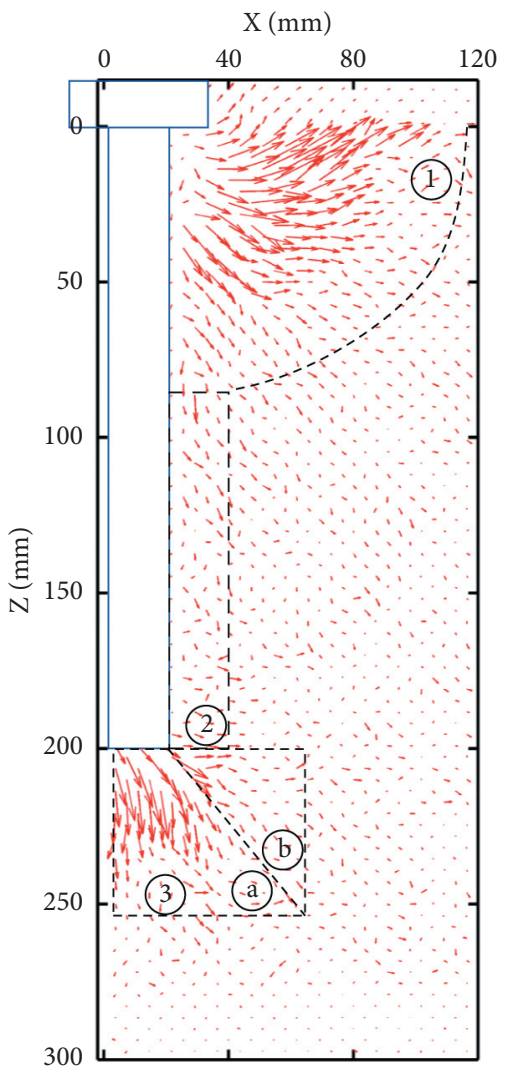

(a)

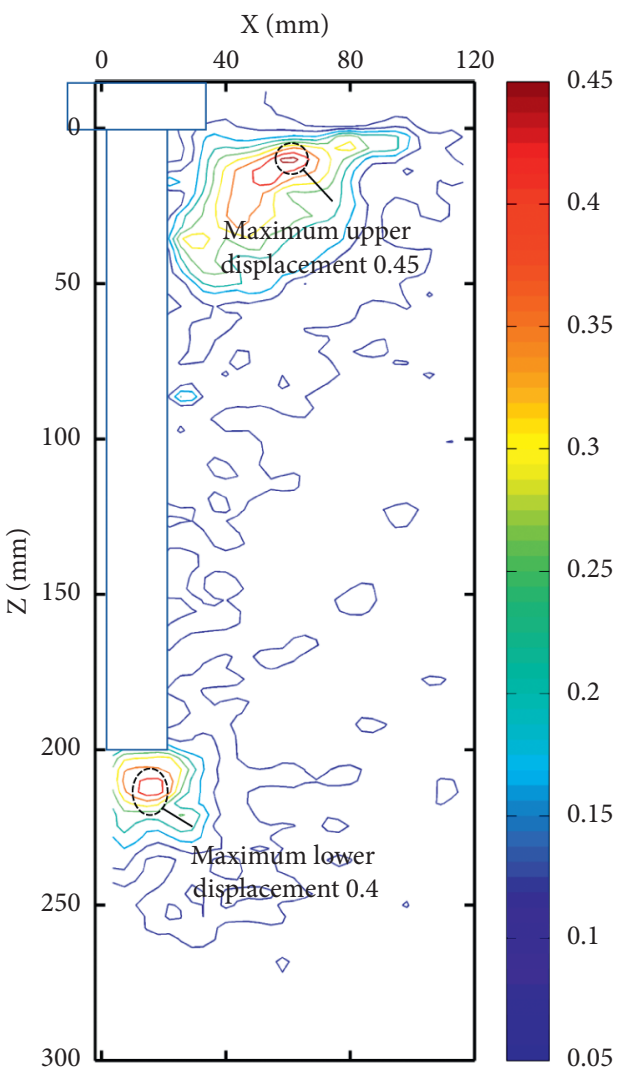

(b)

Figure 12: Vector diagram (a) and contour diagram (b) of soil displacement for intact pile.

with that of intact pile. In Figure 13, in the range of one time pile diameter and from $z=40 \mathrm{~mm}$ to $z=100 \mathrm{~mm}$, the deformation direction of soil around piles is nearly vertical and downward, and the soil develops shear sliding with pile settlement. For SLM pile and SLT pile, the soil deformation at the necking of SLM pile is similar to that of SLW pile, and the soil deformation of SLT pile is pretty obvious. In the range of $z=40 \mathrm{~mm}$ to $z=120 \mathrm{~mm}$ and one time pile parameter, the deformation direction of soil around piles is vertical downward. When 


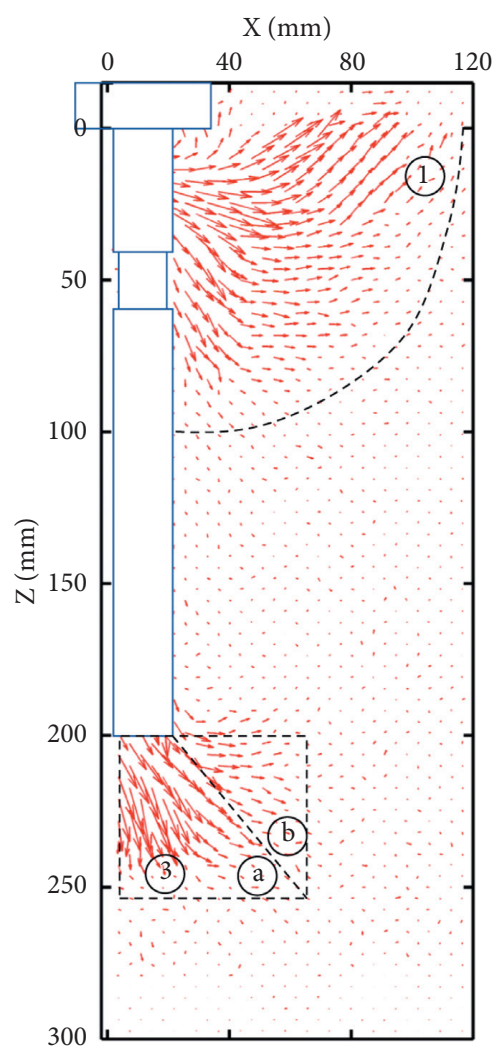

(a)

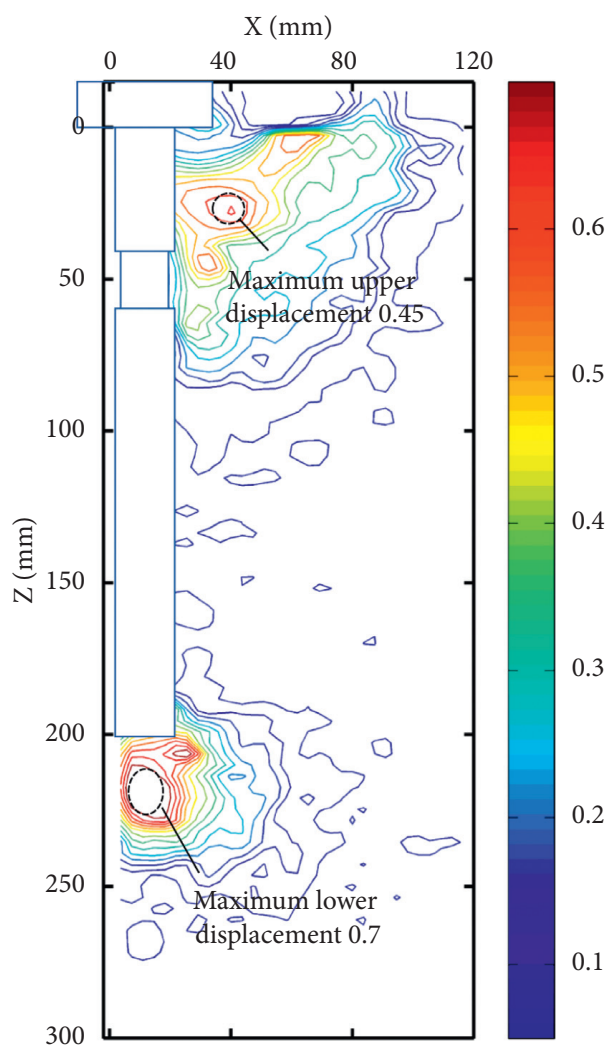

(b)

FIGURE 13: Vector diagram (a) and contour diagram (b) of soil displacement for SLW pile.

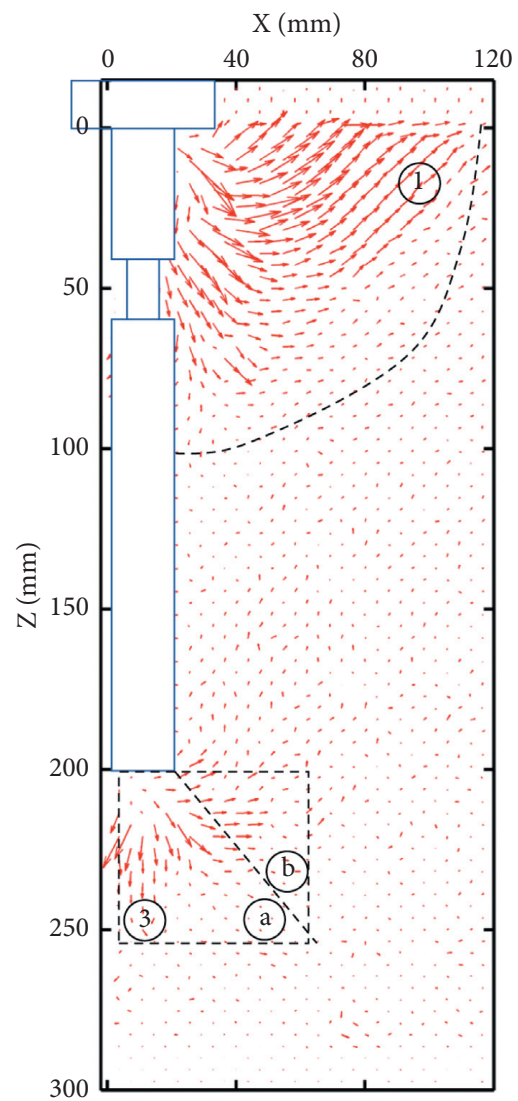

(a)

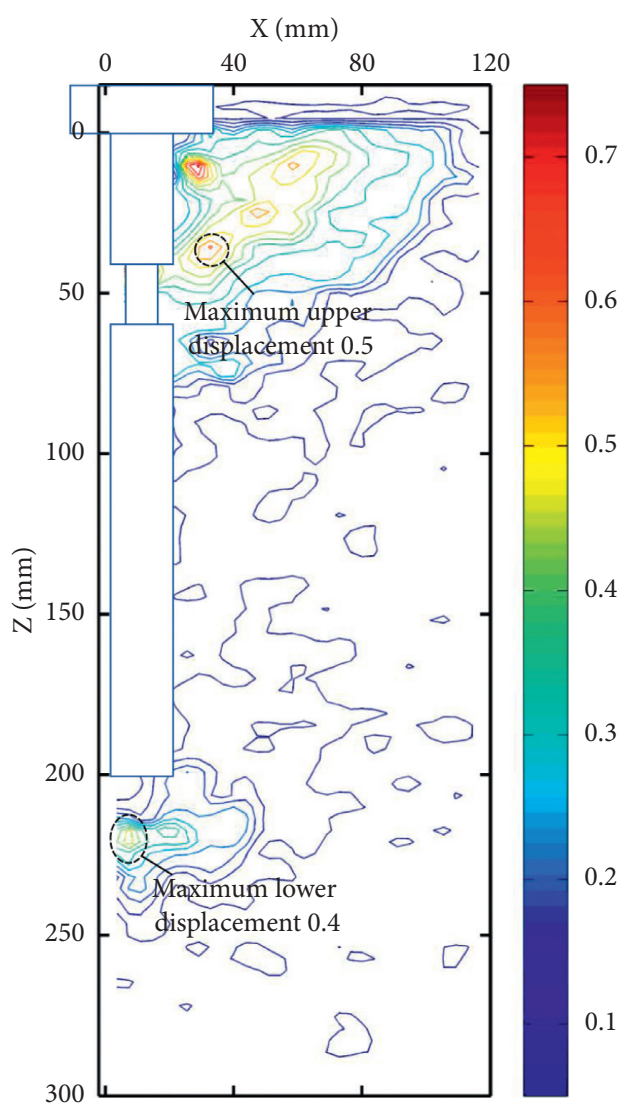

(b)

Figure 14: Vector diagram (a) and contour diagram (b) of soil displacement for SLM pile. 


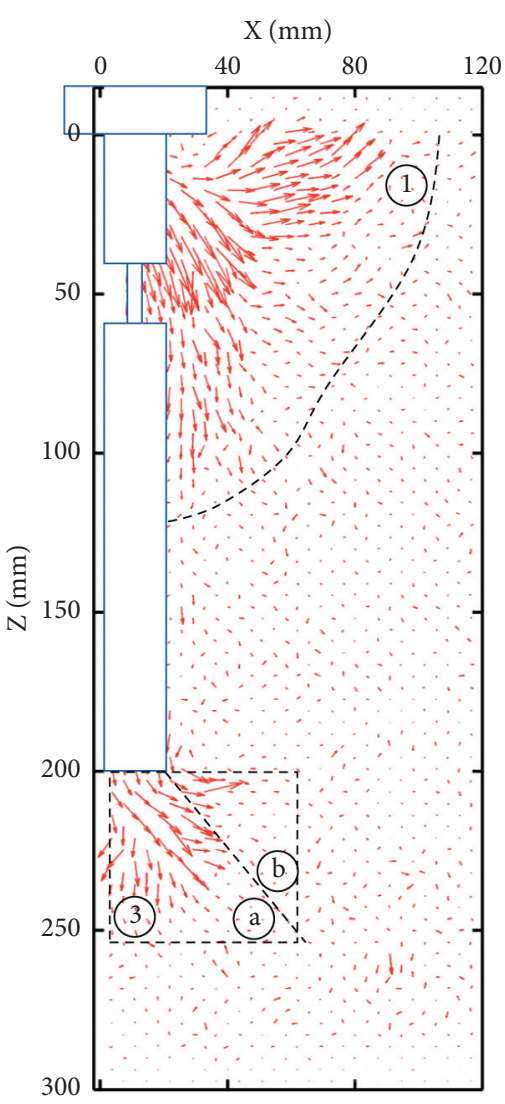

(a)

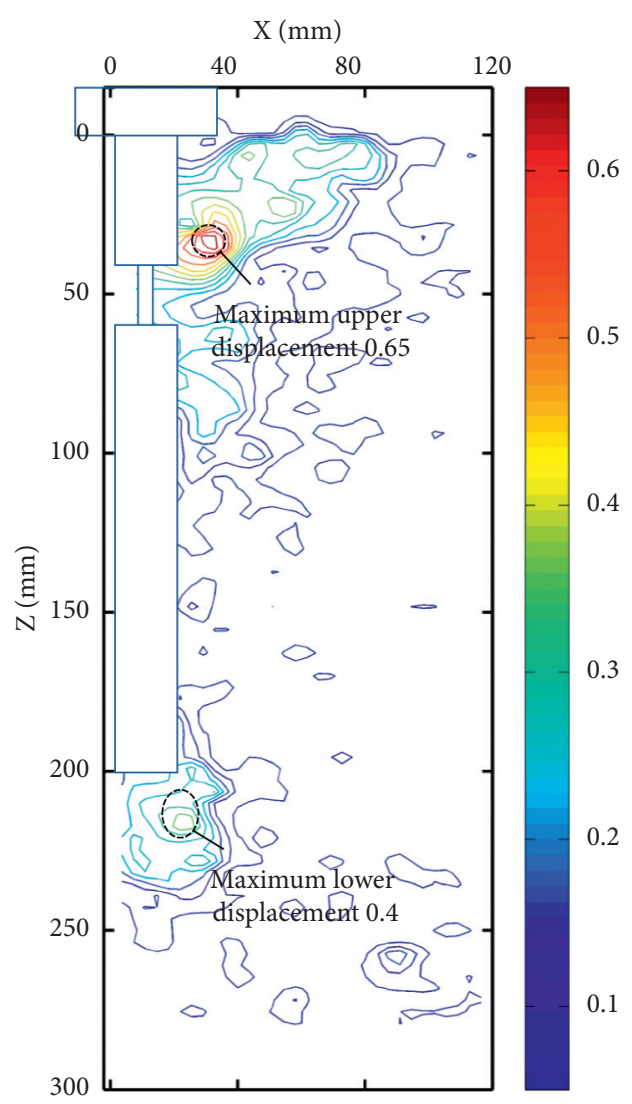

(b)

FIGURE 15: Vector diagram (a) and contour diagram (b) of soil displacement for SLT pile.

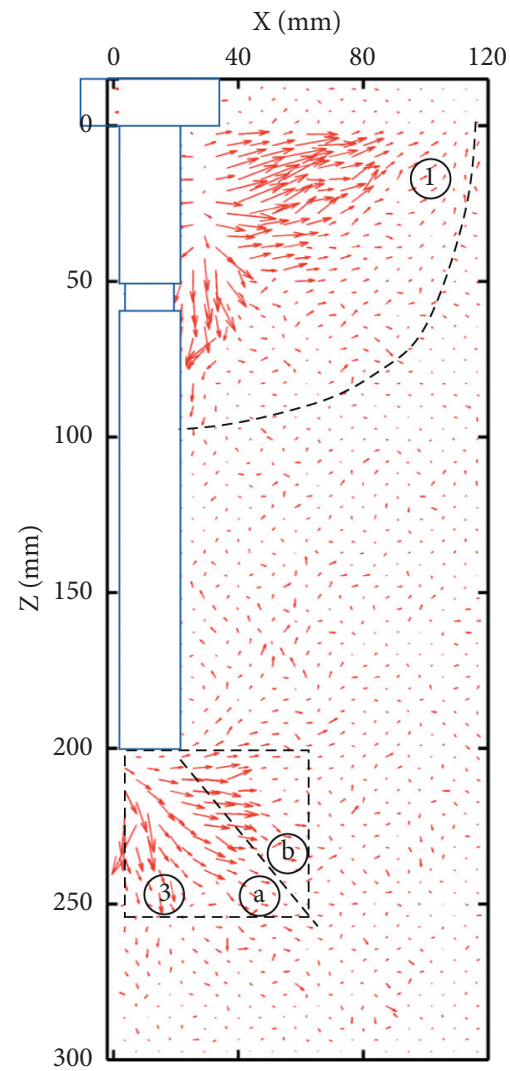

(a)

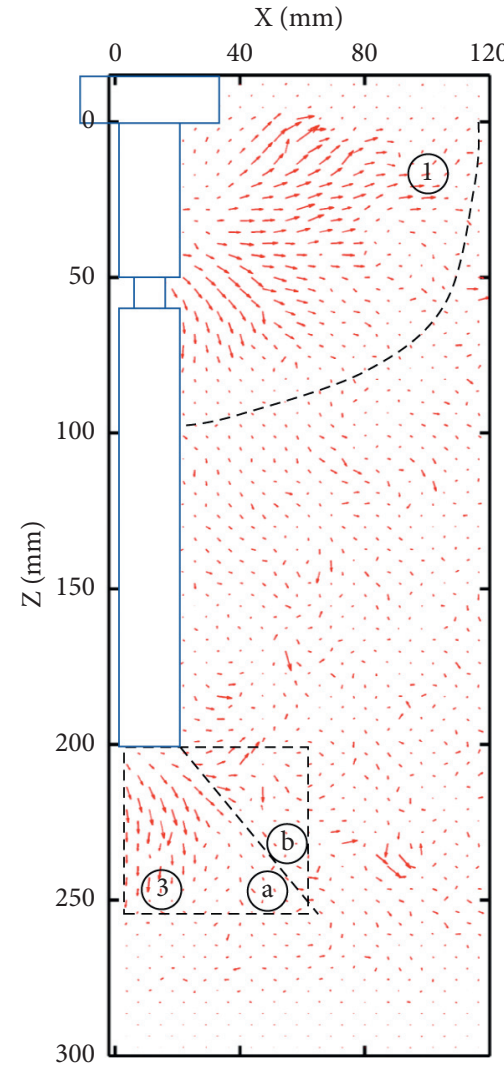

(b)

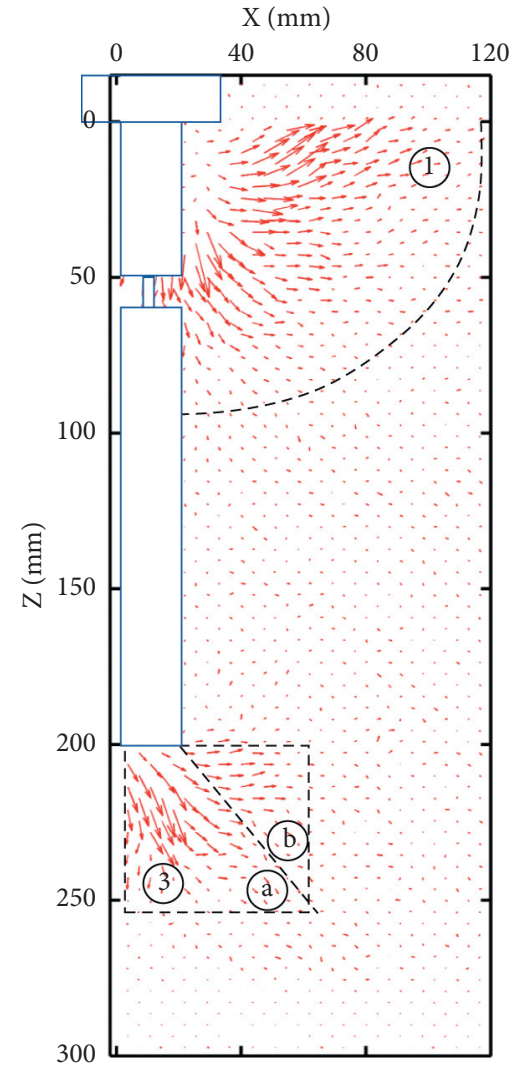

(c)

FIgURE 16: Continued. 


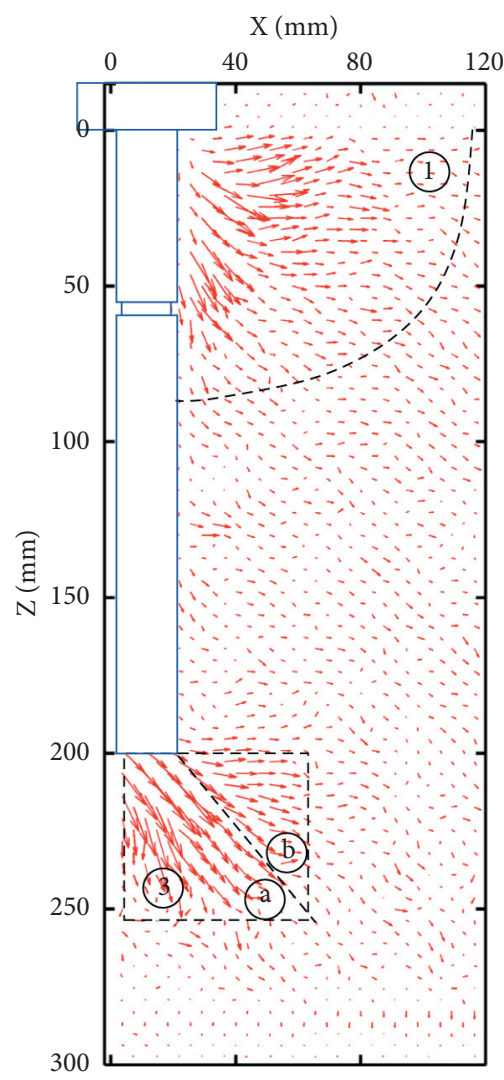

(d)

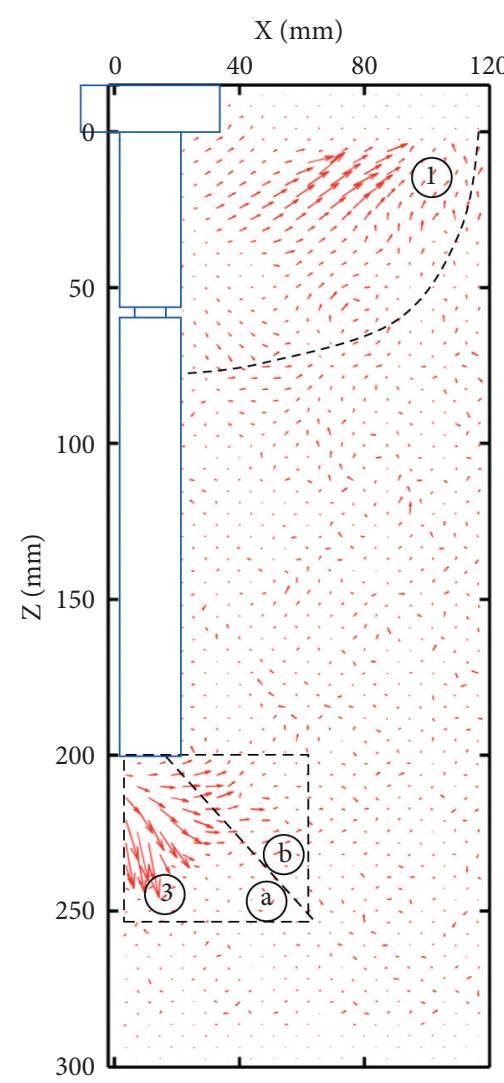

(e)

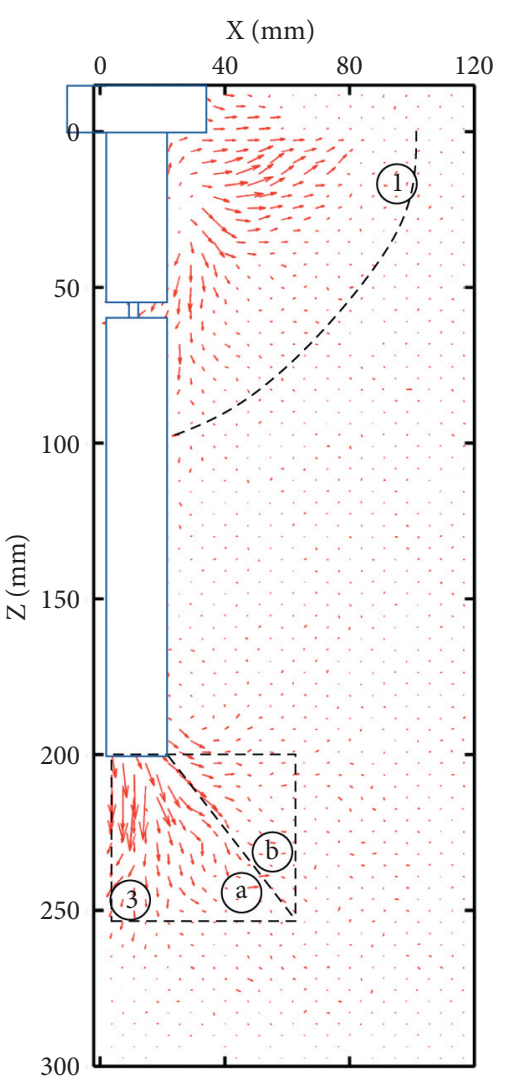

(f)

FIgUre 16: Vector diagrams of (a) SMW pile, (b) SMM pile, (c) SMT pile, (d) SSW pile, (e) SSM pile, and (f) SST pile.

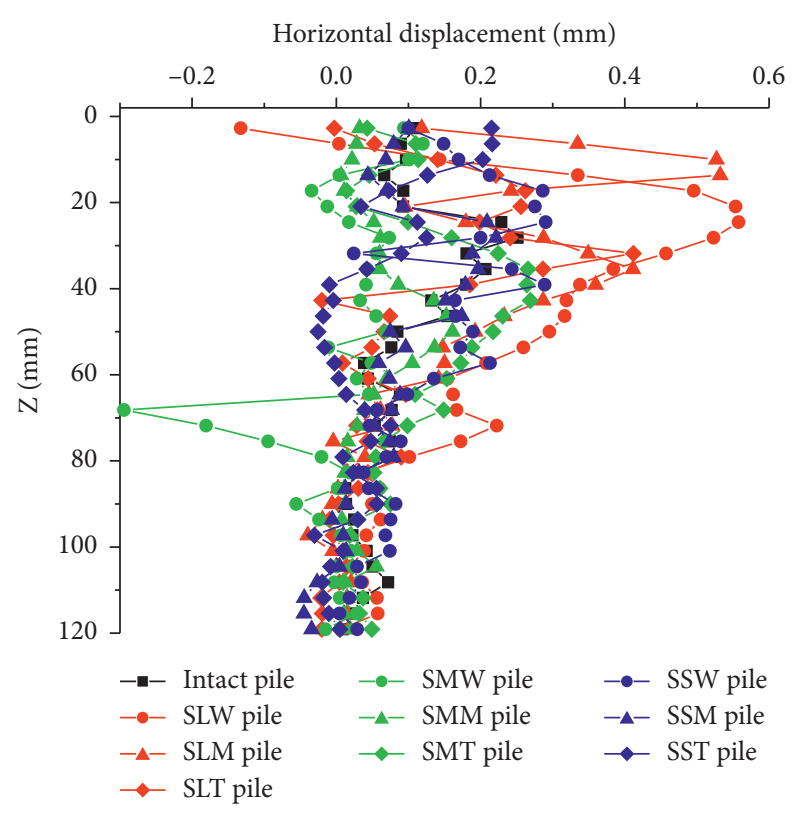

FIGURE 17: Horizontal displacement of the influence area of necking.

$L_{\mathrm{d}}=20 \mathrm{~mm}$, the soil around piles develops obvious shear slip within a certain distance from the top of necking, and the larger the $L_{\mathrm{s}}$ is, the more obvious the shear slip is. As a

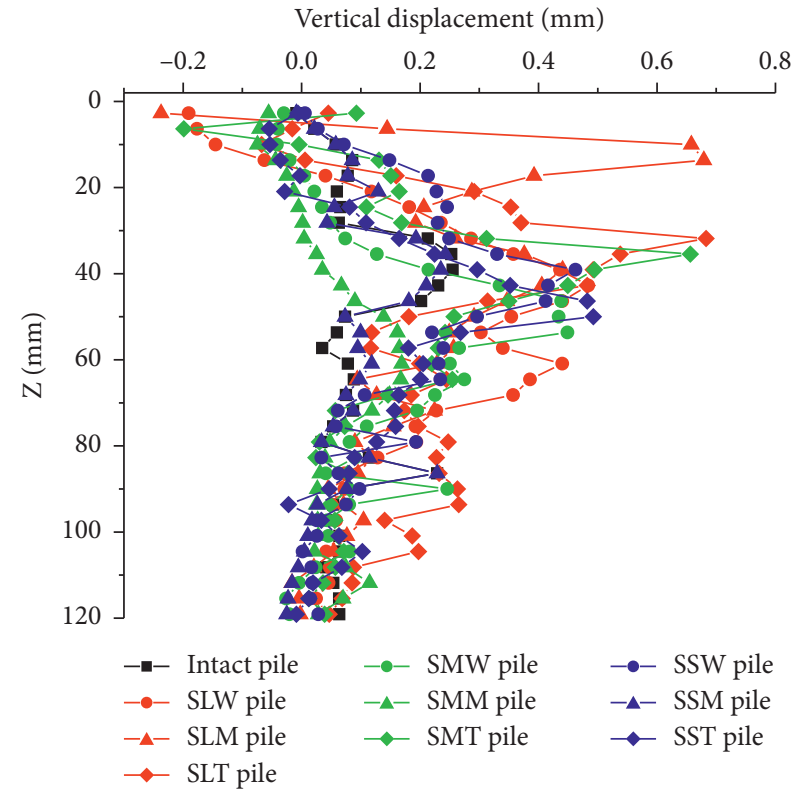

FIGURE 18: Vertical displacement of the influence area of necking.

result, large negative skin friction is produced which causes the vertical bearing capacity of the pile to reduce. Compared with intact pile, the horizontal deformation range of SLT pile in area 1 reduces. The position of the 


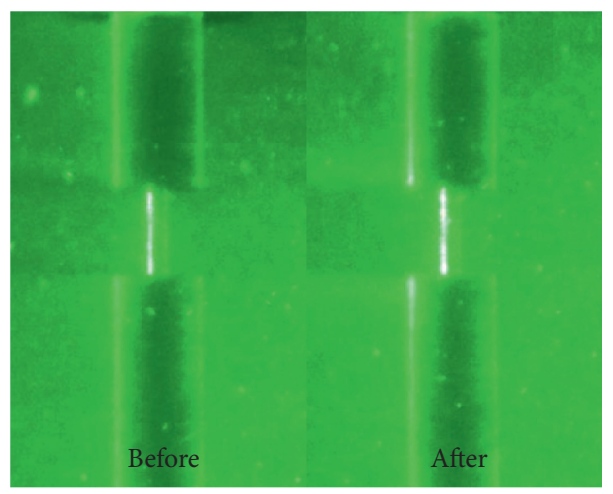

(a)

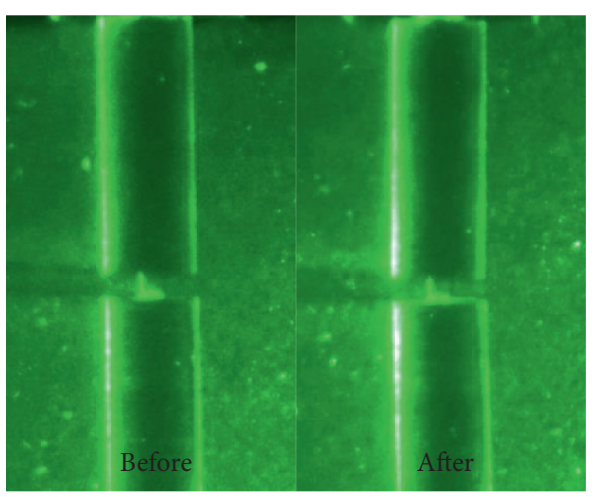

(b)

FIGURE 19: The deformations of SLT pile (a) and SST pile (b) before and after loading.

maximum soil displacement around pile cap is closer to pile shaft. The soil under pile cap undertakes more vertical stress and less horizontal stress. For SLT pile, SLM pile, and SLT pile, the deformations of pile tip are the same as those of intact pile. However, the deformations of soil around pile cap are larger than those of intact pile. Therefore, shallow necking has significant contribution to the soil deformation around pile cap. However, the necking is insensitive to the soil deformation at pile tip. The same results can be obtained from Figure 16. To sum up, the larger the size of necking is, the greater the influence on soil deformation around pile cap is. In addition, when $L_{\mathrm{d}}=5 \mathrm{~mm}$ (2.5\% of pile length), the influence of shallow necking on soil deformation around pile cap is pretty indistinct and only SST pile develops small soil deformation at the necking.

Figures 17 and 18 show horizontal displacement and vertical displacement of soil around necking, respectively. On the whole, horizontal displacement and vertical displacement of the soil of necking pile are greater than those of intact pile, and vertical displacement of the soil of the necking pile is greater than horizontal displacement. Compared with intact pile, vertical displacement of soil below necking ( $z=60 \mathrm{~mm}$ to $Z=120 \mathrm{~mm}$ ) is larger, and the larger necking is, the larger vertical displacement is. Results show that the displacement of soil around pile cap will increase when the necking of the pile cap is shallow, and vertical displacement is mainly generated below necking.

Figure 19 shows the deformation of SLT pile and SST pile before and after loading. After loading, the pile at the top of necking inclines and the upper part of SLT pile inclines to right, which leads piles to become instable or fractured. Therefore, the pile is easy to be damaged when $L_{\mathrm{s}}=4 \mathrm{~mm}$.

\section{Conclusions}

Through transparent soil model experiment, the bearing capacity and displacement field of soil around piles are analyzed using one intact pile with cap and nine shallow necking piles with caps. The following conclusions are obtained:
(1) The vertical bearing capacity of piles with caps will be greatly reduced when the pile shaft has shallow necking. The large of the necking is, the greater the loss of vertical bearing capacity is.

(2) The effect of shallow necking on the soil deformation around pile cap is significant. However, the necking is insensitive to the soil deformation at pile tip. Shallow necking has main contribution to the deformation direction and range of soil around pile cap. Necking can cause the deformation direction of soil under pile cap from inclined downward $45^{\circ}$ to vertical downward, resulting in increasing the soil deformation range under the pile cap and close to the pile shaft and reducing the horizontal deformation range of pile cap.

(3) Shallow necking makes the soil around pile cap develop obvious vertical downward deformation, which causes the relative displacement between pile shaft and soils to reduce. Accordingly, the friction resistance of pile shaft is weakened, and negative friction resistance is easily developed, which causes the vertical bearing capacity of necking piles to greatly lose. When the radial dimension of shallow necking is $4 \mathrm{~mm}$, the pile is easy to be damaged.

\section{Data Availability}

The data used to support the findings of this study are available from the corresponding author upon request.

\section{Conflicts of Interest}

The authors declare that they have no conflicts of interest regarding the publication of this paper.

\section{Acknowledgments}

The authors express their gratitude to the National Natural Science Foundation of China (no. 51978247) and Key Science and Technology Projects of Henan Province (no. 202102310242). 


\section{References}

[1] D. Q. Li, W. H. Tang, and L. M. Zhang, "Updating occurrence probability and size of defect for bored piles," Structural Safety, vol. 30, no. 2, pp. 130-143, 2008.

[2] J.-S. Lee, J. U. Song, W.-T. Hong, and J.-D. Yu, “Application of time domain reflectometer for detecting necking defects in bored piles," NDT \& E International, vol. 100, pp. 132-141, 2018.

[3] C. Schilder, H. Kohlhoff, D. Hoffman et al., "Static and dynamic pile testing of reinforced concrete piles with structure integrated fibre optic strain sensors," Proc SPIE, vol. 8794, no. 5, pp. 47-62, 2013.

[4] S.-H. Ni, Y.-Z. Yang, P.-H. Tsai, and W.-H. Chou, "Evaluation of pile defects using complex continuous wavelet transform analysis," NDT \& E International, vol. 87, pp. 50-59, 2017.

[5] B. Singh, V. V. Arora, V. Patel et al., "Non-destructive testing of bored piles using the low strain pile integrity method," Indian Concrete Journal, vol. 93, pp. 41-48, 2019.

[6] C. H. Wang and J. G. An, "A nonlinear numerical analysis of vertical bearing behavior of bored pile foundations including defective piles with stem shrinkage," Advanced Materials Research, vol. 374-377, pp. 2071-2077, 2012.

[7] M. Iskander, J. Lai, C. Oswald, and R. Mannheimer, "Development of a transparent material to model the geotechnical properties of soil," ASTM Geotechnical Testing Journal, vol. 17, no. 4, pp. 425-433, 1994.

[8] B. X. Yuan, L. Xiong, L. H. Zhai et al., "Transparent synthetic soil and its application in modeling of soil-structure interaction using optical system," Frontiers in Earth Science, vol. 7, p. 276, 2019.

[9] Q. Ni, C. C. Hird, and I. Guymer, "Physical modelling of pile penetration in clay using transparent soil and particle image velocimetry," Géotechnique, vol. 60, no. 2, pp. 121-132, 2010.

[10] C. C. Hurd, Q. Ni, and I. Guymer, "Physical modeling of deformation around piling augers in clay," Geotechnique, vol. 61, no. 11, pp. 993-999, 2011.

[11] G. Q. Kong, Z. H. Cao, H. Zhou, and X.-J. Sun, "Analysis of piles under oblique pullout load using transparent-soil models," Geotechnical Testing Journal, vol. 38, no. 5, pp. 4329-4336, 2015.

[12] Y. Sang, Z. Wang, S. Yu, and H. Zhao, "The loading test on the singe pile with pile cap in transparent soil model," Geotechnical Testing Journal, vol. 42, no. 2, pp. 385-406, 2019.

[13] B. X. Yuan, M. Sun, Y. X. Wang, and L. Zhai, "Full 3D displacement measuring system for 3D displacement field of soil around a laterally loaded pile in transparent soil," International Journal of Geomechanics, vol. 19, no. 5, 2019.

[14] Y. Sang, J. Zhao, F. Duan, W. Sun, and H. Zhao, "A novel automatic device to measure deformation inside transparent soil based on digital image correlation technology," Measurement Science and Technology, vol. 30, no. 3, p. 035202, 2019.

[15] MOHURD, JGJ106-2014, "Technical Code for Testing of Building Foundation Piles", China Architecture \& Building Press, Beijing, China, 2014.

[16] S. Iai, "Similitude for shaking table tests on soil-structure-fluid model in 1 g gravitational field," Soils and Foundations, vol. 29, no. 1, pp. 105-118, 1989.

[17] Z. Y. Li, "Key Problems Investigation on Non-destructive Integrity Detection of Piles with Elevated-Cap (Beam)," Hangzhou, Zhejiang University, Hangzhou, China, 2017.

[18] C. Liu, X. Tang, H. Wei, P. Wang, and H. Zhao, "Model tests of jacked-pile penetration into sand using transparent soil and incremental particle image velocimetry," KSCE Journal of Civil Engineering, vol. 24, no. 6, pp. 1128-1145, 2020.

[19] B. Yuan, M. Sun, L. Xiong, Q. Luo, S. P. Pradhan, and H. Li, "Investigation of 3D deformation of transparent soil around a laterally loaded pile based on a hydraulic gradient model test," Journal of Building Engineering, vol. 28, no. 3, p. 101024, 2020. 